\title{
Phenotypic variation in the familial atypical multiple mole-melanoma syndrome (FAMMM)
}

\author{
HENRY T LYNCH,* RAMON M FUSARO, $\dagger$ WILLIAM A ALBANO, \\ JUDITH PESTER,** WILLIAM J KIMBERLING,§ AND JANE F LYNCH* \\ From the *Department of Preventive Medicine/Public Health, $\uparrow$ Department of Dermatology, \\ $\ddagger$ Division of Oncology, §BoysTown Institute for Communication Disorders in Children and the Institute \\ for Familial Cancer Management and Control, Creighton University School of Medicine, Omaha, \\ Nebraska 68178, USA.
}

SUMMARY The familial atypical multiple mole-melanoma syndrome (FAMMM) is characterised by an autosomal dominantly inherited susceptibility to multiple atypical moles which show variable colouration ranging from black to brown, tan, red, or pink, with occasional variegation. These compound naevi may be macular or papular, with regular or irregular borders, and measure $1 \mathrm{~cm}$ or more in size. They may be few in number or absent or may exceed 100 in a given patient. They are located predominantly on areas not exposed to the sun. Dysplastic changes in melanocytes, fibroplasia, focal chronic inflammatory cell infiltrate, and new blood vessel formation of the papillary dermis characterise their histopathology. These findings are not uniformly present. Because of these distinctive features, coupled with their propensity for transformation to cutaneous malignant melanoma, little attention has been given to the possibility of either minimal or absent cutaneous expression of the phenotype or more diverse neoplastic involvement in this disease. These latter phenomena, which we ascribe to the pleiotropic effects of the cancer-prone FAMMM genotype, were observed in a single FAMMM kindred, the subject of this report.

Variable expressivity of phenotype, including reduced penetrance of the deleterious gene, which is a cardinal feature of dominantly inherited noncancer diseases, ${ }^{1}$ is also frequently observed in cancer genetics. ${ }^{2-4}$ Investigation of virtually all heritable cancer syndromes has shown cancer susceptibility to encompass an array of histological and anatomical sites in any given at risk patient. ${ }^{2} 35$ When studying cancer-prone families, a meticulous assessment of cancer of all anatomical sites is imperative. In early studies of familial breast cancer only site-specific breast cancer was recorded, since the study designs ignored tumours of other anatomical sites. However, it is now clear that genetic heterogeneity accounts for the occurrence of several breast cancer syndromes with differing tumour combinations. ${ }^{46}$ Other examples are common in the discipline of cancer genetics. ${ }^{2} 3$

We postulate that the hereditary variety of malignant melanoma as observed in the FAMMM is more complex than suspected before. For example, intraocular melanoma (IOM) has now been firmly

Received for publication 17 April 1982. shown to be part of the pnenotype of this disease ${ }^{5}$ and tumours of other anatomical sites are probably also associated as a result of the pleiotropic effects of the cancer-prone gene. ${ }^{7}$ Patients have now been observed with an absence of clinical stigmata of the FAMMM, but who, by virtue of their position in their family pedigree, must have the deleterious genotype. ${ }^{8}$ These facts clearly indicate the need for comprehensive clinical-genetic studies of FAMMM kindreds.

The purpose of this report is to document a FAMMM kindred with a wide ranging cutaneous and tumour phenotype.

\section{Family study}

The proband (fig 1, III.4) was a 29-year-old white female. A squamous cell carcinoma of the left tonsillar pillar was surgically resected at the age of 28 (fig 2). A synchronous nodular malignant melanoma (CMM, Clark's level II $^{9}$ ) was excised from the anterior portion of her left forearm and a split-thickness skin graft was performed. This CMM 


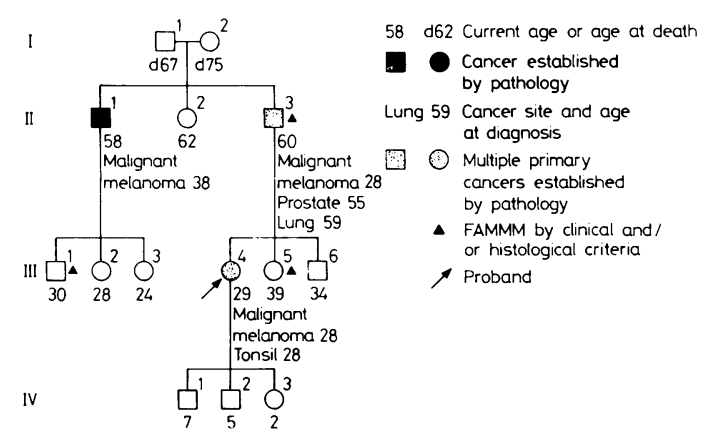

FIG 1 Family pedigree.

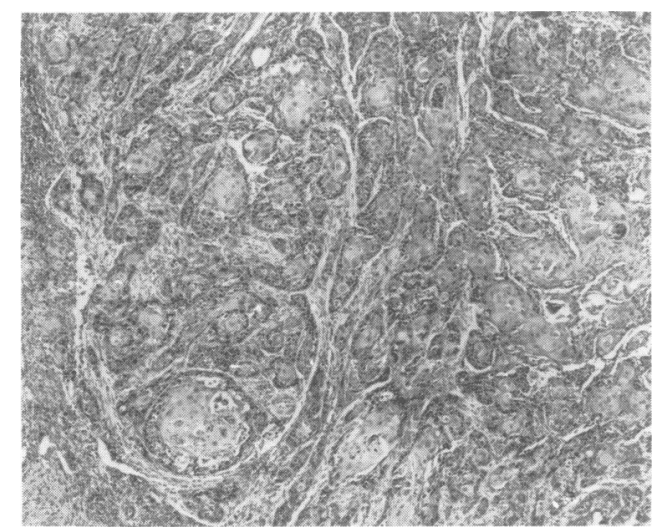

FIG 2 Squamous cell carcinoma of the left tonsillar pillar. (Original magnification, $\times 40$. Haematoxylin and eosin.)

was confirmed by us histologically. Her past medical history was otherwise unremarkable.

She married at the age of 20 . Her first pregnancy was at the age of 21 and was followed by two more term pregnancies. Menarche occurred at 13 years of age and she has had regular menstrual cycles. She began birth control pills at the age of 19 , but discontinued these after only 9 months. She had not been exposed to therapeutic radiation or significant diagnostic $x$-ray procedures. She has not had excessive sunlight exposure. She occasionally smokes (never more than two cigarettes per day) and drinks alcohol only temperately.

Physical examination revealed a patient with auburn hair and brown eyes who had a minimal suntanned complexion, even though she resided in the southern United States. The left side of her tongue had been partially resected. There was a surgical scar on her left anterior forearm secondary to removal of the CMM. Examination of the skin showed an absence of atypical moles. A single $\stackrel{\mathbb{D}}{\rightarrow}$ papular naevus, measuring $0.5 \mathrm{~cm}$, was biopsied and $\overrightarrow{\vec{F}}$ pathological evidence consistent with a FAMMM $\stackrel{5}{+}$ mole was lacking. Laboratory studies, including chest $x$-ray, IVP, bone scan, and CT scan of the brain, were all interpreted as normal.

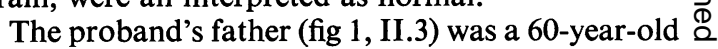
white male. He had contracted malaria during the Second World War while in Africa or Italy after $\vec{\circ}$ discontinuing atabrine, and he may have had a recurrence of this disease in 1951. At the age of $28, \vec{\omega}$ he had had multiple moles (specimens lost) removed S from his right shoulder and back. A lesion on his back was found to be a nodular malignant melanoma, iv Clark's level IV (confirmed by us histologically). ? At the age of 56, a diagnosis of adenocarcinoma $\vec{\sim}$ of the prostate gland was established and he was $G$ treated with radium implants in this gland. He was given diethylstilbestrol and received cobalt treatment $\vec{T}$ over his breasts as prophylaxis. At the age of $58, \mathbb{D}$ he underwent a thoracotomy with left upper lobectomy for histologically proven squamous cell carcinoma of the lung. He smoked 30 cigarettes per day from the age of 16 to 47 . He drank alcohol $\vec{\emptyset}$ temperately.

Physical examination revealed a well-nourished, well-developed white male. He had mild hoarseness. There was a thoracotomy scar on the left, a McBurney's incision, and a suprapubic surgical incision secondary to the prostate operation. There $\mathbb{\otimes}$ was a varicocele of the left superior pole of the testis. The patient did have several atypical naevi which 응 had the clinical appearance of FAMMM moles. Histological findings of these naevi, however, were not characteristic of fully developed FAMMM moles.

The proband's three children were examined by us $\frac{0}{\circ}$ (fig 1, IV.1, IV.2, and IV.3). None showed clinical evidence of atypical moles consistent with the FAMMM syndrome. Their history and physical $\frac{3}{3}$ findings were also unremarkable.

Patient III.1 (fig 1) was examined by a derma- 궁 tologist (HSY) who had clinical experience with other FAMMM syndrome patients. He found the patient to have the classical phenotype of the N FAMMM. The histological examination of one of $N$ these lesions showed a compound naevus with minimal fibroplasia and chronic inflammatory $\omega$ infiltrate of the papillary dermis. There was no melanocytic dysplasia.

Patient III.5 (fig 1) was examined by a dermatol- $\mathscr{\Phi}$ ogist (JLS) and had clinical features of the FAMMM. She had several atypical naevi, but also showed many small macular tan-coloured lesions scattered $\overrightarrow{\mathbb{D}}$ over the trunk. She showed minimal clinical $\frac{\mathcal{P}}{\mathbb{D}}$ features of the more florid clinical phenotype 
previously reported by us. ${ }^{7}$ Two atypical naevi were biopsied and histological examination of these specimens showed compound naevi with mild dysplasia of the melanocytes at the dermal-epidermal junction. One specimen showed a mild chronic infiltrate of the papillary dermis.

Pertinent details of the cutaneous findings and pathology evaluations of moles or malignant neoplasms or both in the kindred are contained in table 1. In summary, this is a single FAMMM kindred showing marked variable expressivity in tumour and cutaneous phenotype. There were three relatives who showed variable clinical and histological cutaneous manifestations of the FAMMM. The proband, who did not have atypical moles, showed a remarkable occurrence of synchronous CMM and squamous cell carcinoma of the oral cavity. Another relative had no cutaneous naevi or associated systemic cancer other than malignant melanoma.

\section{Discussion}

Our study of a relatively small FAMMM kindred demonstrates several important nuances of this recently described disorder. Most striking is the extent of phenotypic variation. Note that the proband (fig 1, III.4) lacked the cutaneous features of the FAMMM, but developed an isolated CMM and, extraordinarily, in the absence of environmental aetiological factors, she manifested a synchronous intraoral carcinoma. In the absence of a reliable biomarker for the FAMMM genotype, we cannot rule out the possibility that these findings were fortuitous. However, when seen in context with the pedigree, it seems more likely that she has expressed the tumour phenotype of the FAMMM. This patient's older sister (III.5) showed clinical

TABLE 1 Cutaneous phenotype and tumour registry of FAMMM kindred.

\begin{tabular}{llll}
\hline Pedigree No & $\begin{array}{l}\text { Clinical } \\
\text { FAMMM } \\
\text { phenotype }\end{array}$ & $\begin{array}{l}\text { FAMMM } \\
\text { histology }\end{array}$ & $\begin{array}{l}\text { Malignant } \\
\text { melanoma }\end{array}$ \\
\hline II.1 & - & - & + \\
II.2 & - & - & - \\
II.3* & + & - & + \\
III.1 & + & + & - \\
III.2 & - & ND & - \\
III.3 & - & - & - \\
III.4† & - & + & + \\
III.5 & + & ND & - \\
III.6 & - & ND & - \\
IV.1 & - & ND & - \\
IV.2 & - & ND & - \\
IV.3 & - & & \\
\hline
\end{tabular}

ND $=$ not done.

*Adenocarcinoma of prostate, squamous cell carcinoma of lung. †Squamous cell carcinoma of tonsil. and pathological features of the FAMMM, but has not yet expressed cancer. Their father (fig 1, II.3) showed clinical cutaneous features of the FAMMM: CMM aged 28, adenocarcinoma of the prostate aged 55 , and squamous cell carcinoma of the lung aged 59. His brother (fig 1, II.1) manifested CMM aged 38. As far as we can determine, he has not shown any cutaneous features of FAMMM moles. However, this patient's son (III.1) shows clinicalpathological features of the FAMMM phenotype.

Histological examination of these compound naevi show variation in the severity of dysplasia of the melanocytes at the dermal-epidermal junction and the amount of fibroplasia and chronic inflammation in the papillary dermis, both within and between patients. In some patients who have the FAMMM phenotype, the naevi histologically show no dysplasia of the melanocytes, but only chronic inflammation and fibroplasia of the papillary dermis. This finding has been demonstrated not only in this family, but in other families studied. ${ }^{3} 7$

From the detailed study of the FAMMM families, it seems that there are variations in the histological composition of the compound naevi. These variations may occur in different patients and they even occur in different regions of the same patient. This finding of histological variability has been described in other genodermatoses, such as neurofibromatosis and connective tissue naevi. It would not be unreasonable to expect a similar degree of variation in the histopathology of the FAMMM naevi.

A preliminary genetic analysis of this and three other kindreds strongly supports the hypothesis of autosomal dominant inheritance. The rate of penetrance was estimated to be approximately 0.86 and is surprisingly almost independent of age. CMM, atypical moles, and multiple primary cancers were, in that order, the best criteria of the affected subjects. This family shows the typical variation in expression observed in the other kindreds. It also displays what we believe to be another important aspect of the FAMMM syndrome. As a disease of the young and middle-aged adult, it is manifest by CMM or atypical moles or both. As a disease of the more elderly, it is manifest as multiple primary cancers usually, although not necessarily, with a history of CMM and atypical moles (fig 1, II.3). These cancers include intraocular melanoma (IOM) and carcinoma of the breast and lung. Proof of this progression of the natural history of the FAMMM diagnosis will require the examination of many more such families.

The study of a single kindred poses serious limitations for the delineation of genetics and phenotype since only a given number of at risk patients can be ascertained. Further confounding this issue is the possibility of genetic heterogeneity 
and the absence of reliable biomarker(s). Several questions therefore must be considered with respect to the FAMMM. (1) Is the dominant gene causing the FAMMM influenced by associated genes, chromosomal position effect, or specific environmental interactions? (2) Are there differing hereditary forms (genetic heterogeneity)? (3) What is the full range of tumour spectrum in the FAMMM? (4) Are there sporadic forms, so called phenocopies, of the FAMMM? (5) How consistent is the expression of the histological features of the FAMMM mole in these patients and is it always the precursor of malignant melanoma (that is, does CMM develop de novo in the kindred)? With respect to extracutaneous tumours, we have recently studied a family from Holland ${ }^{5}$ in which a patient showed cutaneous features of the FAMMM but, in addition, he manifested bilateral IOM and multiple CMMs. Cancer of diverse anatomical sites (lung, breast), including CMMs and cutaneous features of the FAMMM, occurred throughout this Dutch kindred.

Sporadic occurrences of the FAMMM have been reported.1011 However, painstaking clinical and pathology studies of all available high risk relatives of the probands were not described. We have shown that genetic historical data are consistently missed by physicians in the appraisal of cancer-prone families. ${ }^{12}$ Until such data are available, we would prefer to withhold judgment on the status of socalled sporadic occurrences of the FAMMM. For example, when reassessing two allegedly sporadic cases, Elder et $a l^{10}$ found them to have positive family histories. Our family could very well have fitted into the sporadic category had we seen the proband's father in isolation. In turn, the proband $\stackrel{\mathbb{D}}{?}$ would not have been considered to manifest the $\overrightarrow{\vec{F}}$ FAMMM had we not had an opportunity to study her unusual cancer occurrences together with the clinical-pathological findings in her relatives. The fact of reduced penetrance and variable expression $\vec{\nabla}$ further confounds the issue. Both parents will be $\propto$ unaffected $15 \%$ of the time. Consequently, one $\approx$ must evaluate carefully the extended kindred, $\overrightarrow{0}$ including grandparents, aunts, uncles, and cousins. Indeed, experience with other dominant disorders $\vec{\omega}$ showing similar degrees of variation in expression and penetrance has taught the geneticist to use caution in the use of the term sporadic.

It would be premature at this time to split the FAMMM into two formal sub-types, one familial and the other sporadic, and therefore to imply two different aetiologies. A priori, we would expect a proportion, if not all, of sporadic cases to be the result of new mutations at the FAMMM locus. Their familial nature may not be recognised until the next generation. The concept of a FAMMM phenocopy with a different pathogenesis can only be considered a remote possibility, and proof of the phenocopy hypothesis must be supported by rigorous histopathological and family studies.

Experience in cancer genetics has clearly indicated that many cellular types and differing organ and tissue sites may be inordinately susceptible to malignant transformation. ${ }^{2-4}$ An example of variable tumour spectra in several cancer-associated genodermatoses, each of which is believed to be under the control of a single gene, is provided in table $2 .^{13}$

Models at the animal level, such as the Sinclair miniature swine colony, when observed, should be

TABLE 2 Representative tumour associations in several cancer-associated genodermatoses.

\begin{tabular}{|c|c|c|}
\hline Autosomal recessive & Autosomal dominant & $X$ linked recessive \\
\hline $\begin{array}{l}\text { Ataxia telangiectasia (Louis-Bar syndrome) } \\
\text { Lymphocytic leukaemia, Hodgkin's } \\
\text { disease, reticulum cell sarcoma, } \\
\text { lymphosarcoma and other lymphoma, } \\
\text { possible gliomas, medulloblastoma, and } \\
\text { gastric carcinoma }\end{array}$ & $\begin{array}{l}\text { Multiple naevoid basal cell carcinoma } \\
\text { syndrome } \\
\text { Multiple basal cell carcinoma, } \\
\text { medulloblastoma, astrocytoma, } \\
\text { amelioblastoma, ovarian carcinoma }\end{array}$ & $\begin{array}{l}\text { Wiskott-Aldrich syndrome } \\
\text { Lymphoreticular malignancies, malignant } \\
\text { lymphoma, myelogenous leukaemia, } \\
\text { astrocytoma }\end{array}$ \\
\hline $\begin{array}{l}\text { Bloom's syndrome } \\
\text { Leukaemia, lymphomas, squamous cell } \\
\text { carcinoma of the oesophagus, adeno- } \\
\text { carcinoma of the colon }\end{array}$ & $\begin{array}{l}\text { Cowden's disease (multiple hamartoma } \\
\text { syndrome } \\
\text { Carcinoma of breast, colon, and thyroid }\end{array}$ & $\begin{array}{l}\text { Dyskeratosis congenita (Zinsser-Cole-Engman } \\
\text { syndrome) } \\
\text { Squamous cell carcinoma of oral cavity, } \\
\text { oesophagus, nasopharynx, skin, anus, } \\
\text { cervix, and adenocarcinoma of rectum }\end{array}$ \\
\hline $\begin{array}{l}\text { Fanconi pancytopenia (constitutional } \\
\text { infantile panmyelopathy) } \\
\text { Leukaemia, particularly myelomonocytic, } \\
\text { squamous cell carcinoma of mucocutaneous } \\
\text { junctions such as around mouth, tongue, } \\
\text { vulva, and anus }\end{array}$ & $\begin{array}{l}\text { Von Recklinghausen's neurofibromatosis } \\
\text { Sarcomas, intracranial and optic nerve } \\
\text { gliomas, acoustic neurinoma, optic } \\
\text { neuroma, meningiomas, and } \\
\text { phaeochromocytoma }\end{array}$ & \\
\hline $\begin{array}{l}\text { Werner's syndrome } \\
\text { Osteogenic sarcoma, hepatoma, adeno- } \\
\text { carcinoma of the bile duct, breast, thyroid, } \\
\text { malignant melanoma, squamous cell } \\
\text { carcinoma, meningiomas }\end{array}$ & $\begin{array}{l}\text { Gardner's syndrome (intestinal polyposis III) } \\
\text { Adenocarcinoma of colon, periampullary } \\
\text { carcinoma, thyroid carcinoma, adrenal } \\
\text { cortical carcinoma, sarcomas }\end{array}$ & \\
\hline
\end{tabular}


maximally exploited. ${ }^{14}$ We have noted evidence of similarities in the histology of naevi from these swine with that from our FAMMM patients.

Experience is limited with regard to the surveillance and management of the FAMMM syndrome. Findings in our kindred, as well as those from reviewing published reports, clearly show the need for educating both the patient and the physician about the natural history of this disease. Knowledge of the marked variable expressivity of phenotype, including the risk for extracutaneous cancers, must be employed in cancer control strategy.

The risk for the development of isolated de novo malignant melanomas without pre-existing naevi, which differs from the view of Elder et $a l^{10}$ who feel that the atypical mole is invariably the precursor of CMM, must be studied.

The advent of new technology in television and computer image storage/retrieval should in the future enable a clinical comparative review of the entire cutaneous surface with the capability of image intensification and magnification of small areas. This type of surveillance will necessarily be restricted to centres with the capability for this technology as opposed to the typical clinical office setting. This surveillance mode will be cost effective only in at risk family members. The recognition of clinical changes would then necessitate prompt histological examination.

Support for this work was provided by the Nebraska Division of the Fraternal Order of Eagles and the Development Fund of the Department of Dermatology, CNUHF. We wish to thank the following physicians who helped us by examining these patients in various parts of the United States and Puerto Rico and obtaining tissue for histological examination: Hubert M Brown, Robert G Brown, Gerald A Gellin, Samuel L Moschella, S Nagendran, Eric G Olson, R J Rowe, Jorge L Sanchez, and Howard S Yaffee.

\section{References}

1 McKusick VA. Heritable disorders of connective tissue. 4th ed. St Louis: Mosby, 1972.

2 Lynch HT. Cancer genetics. Springfield, Illinois: Thomas, 1976.

3 Lynch HT. Genetics, etiology, and human cancer. Prev Med 1980;9:231-43.

4 Lynch HT. Breast cancer genetics. New York: Van Nostrand Reinhold, 1981.

${ }^{5}$ Lynch HT, Fusaro RM, Pester J, et al. Tumour spectrum in the FAMMM syndrome. Br J Cancer 1981 ;44:553-60.

${ }^{6}$ Lynch HT, Mulcahy GM, Harris RE, Guirgis HA, Lynch JF. Genetic and pathologic findings in a kindred with hereditary sarcoma, breast cancer, brain tumors, leukemia, lung, laryngeal, and adrenal cortical carcinoma. Cancer 1978;42:2055-64.

7 Lynch HT, Fusaro RM, Pester J, Lynch JF. Familial atypical multiple mole-melanoma (FAMMM) syndrome: genetic heterogeneity and malignant melanoma. $B \boldsymbol{r} J$ Cancer 1980;42:58-70.

8 Lynch HT, Frichot BC, Lynch JF. Familial atypical multiple mole-melanoma syndrome. J Med Genet 1978; 15:352-6.

9 Clark WH, Reimer RR, Greene M, et al. Origin of familial malignant melanomas from heritable melanocytic lesions: the B-K mole syndrome. Arch Dermatol 1978;114:732-8.

10 Elder DE, Goldman LI, Goldman SC, Greene MH, Clark WH. Dysplastic nevus syndrome: a phenotypic association of sporadic cutaneous melanoma. Cancer 1980;46:1787-94.

11 Rahbari H, Mehregan AH. Sporadic atypical mole syndrome: a report of five nonfamilial B-K mole syndrome-like cases and histopathologic findings. Arch Dermatol 1981;117:329.

12 Lynch HT, Follett KL, Lynch PM, Albano WA, Mailliard J, Pierson RL. Family history in an oncology clinic: implications concerning cancer genetics. JAMA 1979;242:1268-72.

${ }^{13}$ Lynch HT, Fusaro RM. Cancer-associated genodermatoses. New York: Van Nostrand Reinhold, 1982.

14 Oxenhandler RW, Adelstein EH, Haigh JP, Hook RR, Clark WH. Malignant melanoma in the Sinclair miniature swine. Am J Pathol 1979;96:707-19.

Requests for reprints to Professor H T Lynch, Department of Preventive Medicine/Public Health, Creighton University School of Medicine, Omaha, Nebraska 68178, USA. 